\title{
Payment Reform to Transform Primary Care: What More Is Needed?
}

\author{
Eugene C. Rich, MD \\ Center on Health Care Effectiveness, Mathematica Policy Research, Washington, DC, USA.
}

J Gen Intern Med 33(7):986-8

DOI: $10.1007 / \mathrm{s} 11606-018-4447-1$

(C) Society of General Internal Medicine 2018

$\mathrm{P}$ rimary care has been struggling in the USA for over 50 years. By the 1960 s, the decline in new entrants to general practice led to the Millis Commission report defining essential attributes of the imperiled primary care role, as well as to the establishment of Family Practice (now Family Medicine) as a new specialty dedicated to primary care. ${ }^{1}$ Despite this and other new "generalist" physician pathways to primary care careers (like general internal medicine, general pediatrics, medicine-pediatrics, and geriatrics), medical student interest languished. By the 1990s, US health care cost growth had become a serious concern and policy researchers noted spending appeared to be less in systems with more robust primary care. ${ }^{1,2}$ However, resulting US payment reforms often defined the key role of primary care as "gatekeeping" patient access to specialized care, an image that proved widely unpopular with both consumers and clinicians. By the 2000s, many physicians in titular "primary care" disciplines like family medicine or general internal medicine were shifting into hospitalist or other clinical roles, remaining generalist practices further adapted to new regulations (as well as declining rates) for visit-based payment, and dedicated urgent care practices and retail-based clinics proliferated. In this chaotic environment, payers and policymakers resisted the idea that simply paying higher fees for visits to generalist clinicians would address the problems in primary care. ${ }^{3}$ Accordingly, several national professional associations began advocating for payment reform tied to a more formalized "medical home" model of generalist clinical practice, and in March 2007 agreed on "Joint Principles of the Patient-Centered Medical Home (PCMH).". 4

Since then, numerous efforts have been undertaken by payers to encourage outpatient generalist practices to transform into PCMHs, but thus far results have been mixed. ${ }^{5}$ In this issue, Burton et al. use qualitative methods to add insights to the traditional (and overall cautionary), quantitative findings from the eight state Multi-Payer Advanced Primary Care Practice (MAPCP) Demonstration. ${ }^{5}$ They take advantage of the diversity across states of PCMH program features (as well as diversity of program success) to explore which program elements might have been most effective at achieving

Published online April 20, 2018 impactful practice transformation. They note the presence across the eight state initiatives of $21 \mathrm{PCMH}$ transformation program features observed in their case studies. Only four of these eight state initiatives realized net Medicare Savings for beneficiaries in participating PCMH practices, so these researchers categorize program features as "associated with generating net savings" if they were present in most of the states observing savings and absent in most of the states that did not.

The program features most associated with net savings are not surprising in light of other work on primary care transformation. Considerable time and effort are required to achieve practice site transformation, since the prevalent visit-oriented payment system does not reward PCMH functions. ${ }^{6}$ This imposes a particularly daunting challenge given the relatively brief (often 3 year) duration of this demonstration. Thus, two features noted by Burton et al.-requiring practices to be recognized PCMHs on entry, and not allowing late entrants to the initiative - are both program features that would favor recruitment of practices better poised to succeed. Sustaining the transformation efforts in recruited practices is also challenging, since clinical demands in primary care are always large relative to the resources available to support new initiatives. Accordingly, it is not surprising that programs that "incentivized consistent activities within a state" may have been more successful, as were programs that consistently delivered on the practice expectations for payment/bonus. Finally, since practices need a substantial shift in revenue streams to make financially viable such PCMH-oriented practice reorganization, ${ }^{7}$ it is not surprising that Burton et al. observed that giving practices meaningful opportunities for performance bonuses appeared to be tied to transformation success.

Like other PCMH transformation initiatives, MAPCP programs often attempted to defray the direct (and indirect) cost to the practice of adopting this new mode of care by supporting resources (like care coordinators or practice transformation coaches) from outside the practice. The several MAPCP program features reflecting this type of program strategy were all categorized as "not associated with net savings." The fact that Burton et al. found no signal supporting these features is interesting but perhaps not surprising. Evaluation of earlier CMS care coordination demonstrations suggested the level of engagement of care coordinators in the primary care practice was an important success factor. ${ }^{8}$ It is plausible that quickly making effective use of these outside resources was not easy for busy practices, especially in view of the diversity of 
transformation support models, practice settings, patient populations, and communities.

What is more noteworthy in this report is the relative lack of transformation attention toward the key primary care features of access, continuity, and comprehensiveness, which, like care coordination, are under-supported by visit-based payment methods. ${ }^{6}$ The overall PCMH principles (and related certification programs) impose on practices some requirements for enhanced access and for continuing care by an identified personal clinician. The authors did not describe any program activities focused on continuity, which can still vary considerably in PCMH-certified practices operating in the highly fragmented US health care system. Regarding access, Burton et al. reported on only one relevant activity, offering "roundthe-clock access to care," observing this as a practice requirement in only three of the eight states. Comprehensiveness is the other essential feature of primary care, inherent to its roots in "general practice." This aspect of primary care has been strongly discouraged by current fee for service billing policies which reward a "document and refer" approach to patients, and variations in comprehensiveness across practices have been associated with excess hospitalizations and Medicare spending. ${ }^{10}$ However, PCMH certification criteria have not addressed this in a substantive way, and Burton et al. report no transformation activities focused on enhancing this aspect of primary care.

MAPCP relies on PCMH certification as a means of practices documenting primary care transformation, an approach commonly used by payers who may be reluctant to offer generalist practices enhanced payments without some assurance of a shift in care processes. Nonetheless, as noted above, meeting these certification requirements may be insufficient to assure the adequate provision of core primary care functions within a practice. While Burton et al. note that in their study, "the longer a practice has been operating as a PCMH, the more likely they are to generate net savings." This finding could reflect selection of the types of practices likely to engage in such certification, instead of the transformative power of certification per se. For practices adapted to traditional payment models, tying payment reform to PCMH certification is certainly preferable to "pay for performance" based on a distracting (and largely irrelevant) array of care process metrics. And the Burton study can provide no insights regarding the benefits of NCQA's recently updated process for PCMH certification. ${ }^{11}$ Nonetheless, it is plausible that simpler transformation initiatives sending practices more clear signals regarding meaningful enhancements in access, continuity, coordination, and comprehensiveness, may also prove to be effective.

Of course, another essential element of the PCMH Principles is primary care payment reform. Both the structure of the payment model and the relative amount may be important to meaningful restoration of the core features of primary care to generalist practices. Given the aforementioned limitations of visit-oriented payments for supporting primary care functions, a number of alternatives have been proposed for "buying a medical home.". ${ }^{12}$ The MAPCP payment model involved a modest per beneficiary per month (PBPM) payment supplementing traditional fee-for-service, similar to approaches used in a variety of PCMH transformation demonstrations. ${ }^{13}$ Given the limited variations allowed under the MAPCP demonstration, the work by Burton et al. can offer few insights on the effectiveness of alternative payment approaches. A more dramatic change in payment model involves payers offering reduced payments for face-to-face services combined with a larger per patient payment; this is currently being tested by the Center for Medicare and Medicaid services (CMS) as the Track 2 version of the Comprehensive Primary Care Plus initiative. Even more radical is eliminating all visitbased primary care payments, and replacing these with a PBPM payment to cover all primary care services. This approach was recently recommended for CMS testing by the Physician-Focused Payment Model Technical Advisory Committee. ${ }^{14}$

US policymakers have yet to discern a payment reform that can reliably restore access, continuity, coordination, and comprehensiveness to generalist practices. New primary care policy initiatives are currently testing several combinations of practice requirements, payment models, and performance measures. Robust mixed method evaluations such as that reflected in the work of Burton et al. can clarify which reform features are most effective at transforming struggling generalist practices into the sources of primary care patients' need. Hopefully, the resulting primary care payment policies will reflect the truism "you can depend on Americans to do the right thing...." because we certainly seem to have "... exhausted every other possibility."

Corresponding Author: Eugene C. Rich, MD; Center on Health Care Effectiveness Mathematica Policy Research, 1100 First Street NE, Washington, DC 20002, USA (e-mail: ERich@mathematica-mpr.com).

\section{Compliance with Ethical Standards:}

Conflict of Interest: The author declares he has no conflicts of interest.

\section{REFERENCES}

1. Institute of Medicine (U.S.). Division of Health Care Services. Committee on the Future of Primary Care, Donaldson MS. Primary care : America's health in a new era. Washington, D.C.: National Academy Press; 1996.

2. O'Malley AS, Rich EC, Maccarone A, DesRoches CM, Reid RJ. Disentangling the Linkage of Primary Care Features to Patient Outcomes: A Review of Current Literature, Data Sources, and Measurement Needs. J Gen Intern Med 2015;30 Suppl 3:S576-85.

3. Medicare Payment Advisory Commission. Report to Congress: Reforming the Delivery System. Washington, DC: Medicare Payment Advisory Commission; 2008 June 2008. Report No.: 1

4. Joint Principles of a Patient-Centered Medical Home [Internet]. American Academy of Family Physicians. 2007 [updated March 5 2007]. Available from: http://www.aafp.org/online/en/home/media/releases/2007/ 20070305pressrelease0.html.

5. Burton RA, Lallemand NM, Peters RA, Zuckerman S. Characteristics of Patient-Centered Medical Home Initiatives that Generated Savings for 
Medicare: A Qualitative Multi-Case Analysis. J Gen Intern Med. https:// doi.org/10.1007/s11606-018-4309-x

6. Berenson RA, Rich EC. US approaches to physician payment: the deconstruction of primary care. J Gen Intern Med 2010;25(6):613-8.

7. Basu S, Phillips RS, Song Z, Bitton A, Landon BE. High Levels of Capitation Payments Needed To Shift Primary Care Toward Proactive Team And Nonvisit Care. Health Aff (Millwood) 2017;36(9):1599-605.

8. Brown RS, Peikes D, Peterson G, Schore J, Razafindrakoto CM. Six features of Medicare coordinated care demonstration programs that cut hospital admissions of high-risk patients. Health Aff (Millwood) 2012;31(6):1156-66.

9. O'Malley AS, Rich EC. Measuring Comprehensiveness of Primary Care: Challenges and Opportunities. J Gen Intern Med 2015;30 Suppl 3:S56875 .
10. Bazemore A, Petterson S, Peterson LE, Phillips RL, Jr. More Comprehensive Care Among Family Physicians is Associated with Lower Costs and Fewer Hospitalizations. Ann Fam Med 2015;13(3):206-13.

11. Information for Practices Recognized Under PCMH 2011 and PCMH 2014 Standards [Internet]. Washington, DC: National Committee for Quality Assurance; 2017 [cited February 15, 2018]. Available from: http://www. ncqa.org/programs/recognition/practices/patient-centered-medicalhome-pcmh/pcmh-redesign.

12. Berenson RA, Rich EC. How to buy a medical home? Policy options and practical questions. J Gen Intern Med 2010;25(6):619-24.

13. Bitton A, Martin C, Landon BE. A nationwide survey of patient centered medical home demonstration projects. J Gen Intern Med 2010;25(6):584-92.

14. AAFP Payment Model Wins Committee's Support [Internet]. Kansas City, Kansas: American Academy of Family Physicians; 2018 [updated January 9, 2018; cited February 15, 2018]. Available from: https://www.aafp. org/news/blogs/inthetrenches/entry/20180109ITT_PTAC.html. 